\title{
AN ANTIMICROBIAL ALKALOID AND OTHER METABOLITES PRODUCED BY Penicillium sp. AN ENDOPHYTIC FUNGUS ISOLATED FROM Mauritia flexuosa L. f.
}

Hector Henrique Ferreira Koolen*, Elzalina Ribeiro Soares, Felipe Moura Araújo da Silva, Richardson Alves de Almeida e Afonso Duarte Leão de Souza

Departamento de Química, Universidade Federal do Amazonas, Av. Gal. Rodrigo Otavio, 3000, 69077-000 Manaus - AM, Brasil Lívia Soman de Medeiros e Edson Rodrigues Filho

Departamento de Química, Universidade Federal de São Carlos, Rod. Washington Luiz, km 235, 13565-905 São Carlos - SP, Brasil Antonia Queiroz Lima de Souza

Escola Superior de Ciências da Saúde, Universidade do Estado do Amazonas, Av. Carvalho Leal, 1777, 69065-001 Manaus - AM, Brasil

Recebido em 20/7/11; aceito em 4/11/11; publicado na web em 20/1/12

\begin{abstract}
The alkaloid glandicoline B (1) and six other compounds: ergosterol (2), brassicasterol (3), ergosterol peroxide (4), cerevisterol (5), mannitol (6) and 1-O- $\alpha$-D-glucopyranoside (7) were isolated from Penicillium sp. strain PBR.2.2.2, a fungus from Mauritia flexuosa roots. The structures of the isolated metabolites were established by spectral analysis. $\mathrm{MeOH}$ extract of the fungal mycelium at 500 $\mu \mathrm{g} \mathrm{mL}{ }^{-1}$ exhibited antimicrobial activity against Staphylococcus aureus and the compound $\mathbf{1}$ at $100 \mu \mathrm{gL}^{-1}$ was active against $S$. aureus, Micrococcus luteus and Escherichia coli. The relationship between the bioactive properties of the fungus PBR.2.2.2 and those achieved for glandicoline B, as well the potential of this substance as bactericide is discussed.
\end{abstract}

Keywords: Penicillium; Mauritia flexuosa; glandicoline B.

\section{INTRODUCTION}

Plant-associated microorganisms are well known as great producers of natural products, being rich sources for biologically active metabolites with a wide-ranging application. ${ }^{1}$ Their ability to use different solid substrates for their own metabolism, including vegetal sources, makes them a very interesting biochemical-chemical agent in nature, specially interfering in the host-plant development. ${ }^{2}$ The host Mauritia flexuosa L. f. is a big palm tree from the Arecaceae family widespread by all South America. ${ }^{3}$ Its main constituents are flavonoids and triterpenoids. ${ }^{4}$ Plants of this species are used in the Amazonian folk-medicine, for burns and used as vermifuge. ${ }^{3}$ The fruits of this palm trees are also used to produce biofuels, cosmetics and as food by the local population.

The Penicillium genus comprises more than 200 species, distributed through the entire world, being found in the most uncommon environments, such as the permafrost soil of the Artic, ${ }^{6}$ some waste water from mines, ${ }^{7}$ and deep ocean sediments. ${ }^{8}$ Fungi from this genus are known as great producers of bioactive metabolites such as antimicrobial, ${ }^{9}$ immunosuppressants and cholesterol-lowering agents, ${ }^{10}$ anti-HIV ${ }^{11}$ and antitumor drugs. ${ }^{8}$ Endophytes are a poorly investigated group of microorganisms that represent an abundant and dependable source of bioactive and chemically novel compounds with potential for exploitation in a wide variety of medical, agricultural, and industrial arenas. ${ }^{12}$ In this context, the present work describes the isolation of some compounds from the Penicillium strain PBR.2.2.2 associated with the Amazonian palm tree $M$. flexuosa and their antibacterial activities.

\section{RESULTS AND DISCUSSION}

The EtOAc extract from the mycelial mass of the Penicillium sp. PBR 2.2.2 was chromatographed on silica gel columns and preparative

*e-mail: hectorkoolen@gmail.com
HPLC to give seven compounds (1-7) (Figure 1). The compounds 2-7 were identified as ergosterol, ${ }^{13}$ brassicasterol,${ }^{14}$ ergosterol peroxide, ${ }^{15}$ cerevisterol, ${ }^{16}$ mannitol, ${ }^{17}$ and $1-O-\alpha-D$-glucopyranoside. ${ }^{18}$<smiles>C=CC(C)(C)C12C=C(O)C(=O)N3C(=Cc4c[nH]cn4)C(=O)NC1(N(O)c1ccccc13)N2O</smiles>

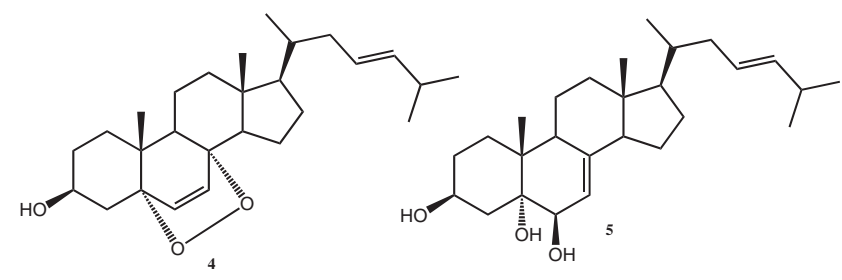<smiles>OC[C@@H](O)C(O)[C@H](O)CO</smiles><smiles>COC1O[C@H](CO)[C@@H](O)[C@H](O)[C@H]1O</smiles>

Figure 1. Structures from the isolated compounds 1-7

Compound 1 was obtained as a yellow gum. Its ${ }^{13} \mathrm{C}$ NMR spectrum exhibited 22 signals which were assigned, by DEPT 135 and HSQC experiments to two methyls, one methylene, nine methines and ten quaternary carbons. Its APCI-MS spectrum contains an ion peak of $[\mathrm{M}+\mathrm{H}]^{+}$at $\mathrm{m} / \mathrm{z} 420$, consistent with the molecular formula $\mathrm{C}_{22} \mathrm{H}_{21} \mathrm{~N}_{5} \mathrm{O}_{4}$ which also was in accordance with the NMR data. The 
identification of $\mathbf{1}$ as the indole alkaloid glandicolin B (Figures 2-3) was made sure as follow. Its ${ }^{1} \mathrm{H}$ NMR spectrum showed two duplets-like signals at $\delta_{\mathrm{H}} 7.57(\mathrm{H}-4)$ and $6.96(\mathrm{H}-7)$ along with two triplets at $\delta_{\mathrm{H}} 7.24(\mathrm{H}-6)$ and $7.01(\mathrm{H}-5)$, all signals with coupling constant of $J=7.7 \mathrm{~Hz}$, characteristics of an orto bi-substituted aromatic ring, which was confirmed by the COSY correlations of H-5 with H-4 and $\mathrm{H}-6$, together with the correlation of H-6 and H-7. Besides, the HMBC correlations of these hydrogen atoms were useful to determine the six aromatic carbons and the $\mathrm{C}-3$, at $\delta_{\mathrm{c}} 54.3$, which was detected in correlation with the $\mathrm{H}-4$. This aromatic ring was achieved as part of the indole skeleton of $\mathbf{1}$ principally by the HMBC correlations among the signal at $\delta_{\mathrm{H}} 5.37(1 \mathrm{H}, \mathrm{s}, \mathrm{H}-8)$ with the $\mathrm{C}-3$ as well with the signals at $\delta_{c} 103.5(\mathrm{C}-2), 127.8(\mathrm{C}-3 \mathrm{a}), 144.4(\mathrm{C}-9)$ and $161.0(\mathrm{C}-10)$. The isoprenyl unit could be verified by the HMBC correlations of hydrogen signals at $\delta_{\mathrm{H}} 1.32(3 \mathrm{H}, \mathrm{s}, \mathrm{H}-24), 1.29(3 \mathrm{H}, \mathrm{s}, \mathrm{H}-25), 5.10$ $(1 \mathrm{H}, d d, J=10.8,16.0, \mathrm{H}-23 \mathrm{cis})$ and $5.03(1 \mathrm{H}, d d, J=16.0,17.2$, $\mathrm{H}-23$ trans) with the carbon signal at $\delta_{\mathrm{C}} 43.6(\mathrm{C}-21)$ as well by the COSY correlations of both $\mathrm{H}-23$ one each other and with the methine hydrogen at $\delta_{\mathrm{H}} 6.22(1 \mathrm{H}, d d, J=10.8,17.2, \mathrm{H}-22)$. The $\mathrm{H}-24$ and $\mathrm{H}-25$ also have $\mathrm{HMBC}$ correlation with the $\mathrm{C}-3$ ratifying this carbon as the connection point of the isoprenyl group of $\mathbf{1}$. Finally the histidine group was indicated by the deshielded signals at $\delta_{\mathrm{H}} 8.26$ $(1 \mathrm{H}, \mathrm{s}, \mathrm{H}-15), 7.90(1 \mathrm{H}, \mathrm{s}, \mathrm{H}-18)$ and $7.37(1 \mathrm{H}, \mathrm{s}, \mathrm{H}-20)$ and their HMBC correlations: $\mathrm{H}-15$ with carbon signals at $\delta_{\mathrm{c}} 167.2(\mathrm{C}-13)$, $131.4(\mathrm{C}-20)$ and $127.4(\mathrm{C}-12), \mathrm{H}-18$ with a signal at $\delta_{\mathrm{c}} 128.8(\mathrm{C}-$ $16)$ and the $\mathrm{C}-20$, and $\mathrm{H}-20$ with a signal at $\delta_{c} 137.6(\mathrm{C}-18)$ and the $\mathrm{C}-16$. While no correlation could be observed between the histidine moiety and the remainder of $\mathbf{1}$, the chemical shifts of C-12, C-13 and $\mathrm{C}-2$, all non-hydrogenated carbons, are in coherence with the known structure of glandicolin B. Since this substance is the direct precursor to meleagrin which is the $O$-methylated version of the glandicoline $\mathrm{B}$, its absolute configurations on the double bond between $\mathrm{C}-12$ and $\mathrm{C}-15$ and on the $\mathrm{C}-2$ and $\mathrm{C}-3$ were deduced as $E, S$ and $R$, respectively, as established by crystallography for meleagrin. ${ }^{19}$ All NMR data obtained for $\mathbf{1}$ are in the Table 1.

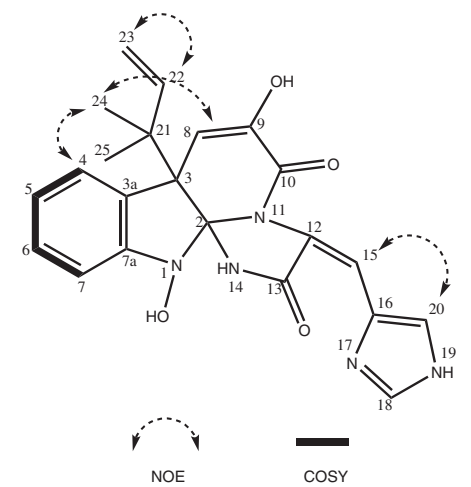

Figure 2. ${ }^{1} \mathrm{H}-{ }^{l} \mathrm{H}$ NOE and COSY correlations for the compound $\mathbf{1}$

The CID spectra of the product ions of the peak at $m / z, 420$ at 15 $\mathrm{eV}$ also confirmed 1, mainly by the fragments at $\mathrm{m} / \mathrm{z} 351$ and 334 corresponding to the losses of the isoprenyl and hydroxyl groups respectively, the ion 289 corresponds to a formamide loss from $\mathrm{m} / \mathrm{z}$ 334. The ions at $\mathrm{m} / \mathrm{z}, 261$ and 233 are derived from CO losses from the ion at $m / z, 289$.

Isolation of Glandicoline B has been published only once previously, from a soil strain of Penicillium glandicola,${ }^{20}$ and its identification was done by comparison between its ${ }^{1} \mathrm{H}$ NMR (acetone-d6), IR, UV and MS (EI) spectra and meleagrin data. All NMR (methanold4) and MS (APCI) data of $\mathbf{1}$ are published for the first time for glandicoline B. This substance is an important intermediate in the

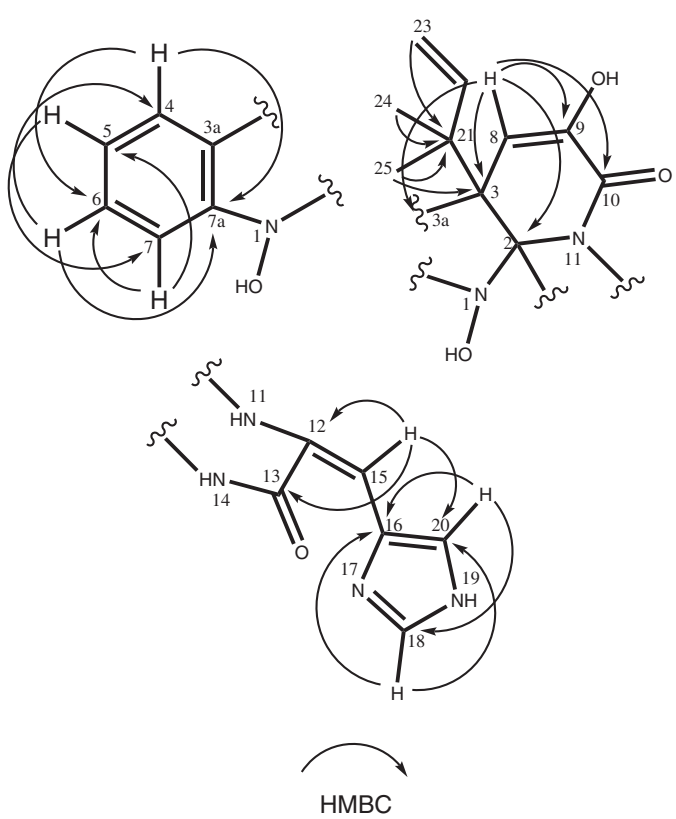

Figure 3. ${ }^{1} \mathrm{H}_{-}{ }^{13} \mathrm{C}$ HMBC correlations for the compound 1

Table 1. Spectral data of compound $\mathbf{1}, \delta$ in ppm $\left({ }^{1} \mathrm{H}, 500 \mathrm{MHz} ;{ }^{13} \mathrm{C}, 125 \mathrm{MHz}\right)$

\begin{tabular}{|c|c|c|c|c|c|}
\hline & $\delta_{\mathrm{c}}$ & $\delta_{\mathrm{H}}$, mult, $(J$ in $\mathrm{Hz})$ & COSY & HМBC & NOE \\
\hline 1 & - & & & & \\
\hline 2 & 103.5 & & & & \\
\hline 3 & 54.3 & & & & \\
\hline $3 a$ & 127.8 & & & & \\
\hline 4 & 125.8 & 7.57, d, (7.7) & H5 & $\mathrm{C} 3, \mathrm{C} 6, \mathrm{C} 7 \mathrm{a}$ & $\mathrm{H} 24$ \\
\hline 5 & 123.7 & 7.01, t, (7.7) & $\mathrm{H} 4, \mathrm{H} 6$ & $\mathrm{C} 3 \mathrm{a}, \mathrm{C} 7$ & \\
\hline 6 & 129.4 & $7.24, \mathrm{t},(7.7)$ & $\mathrm{H} 5, \mathrm{H} 7$ & $\mathrm{C} 4, \mathrm{C} 7 \mathrm{a}$ & \\
\hline 7 & 113.1 & $6.96, \mathrm{~d},(7.7)$ & H6 & $\mathrm{C} 3 \mathrm{a}, \mathrm{C} 5$ & \\
\hline $7 \mathrm{a}$ & 149.8 & & & & \\
\hline 8 & 110.8 & $5.37, \mathrm{~s}$ & & $\mathrm{C} 2, \mathrm{C} 3, \mathrm{C} 3 \mathrm{a}, \mathrm{C} 9, \mathrm{C} 10$ & $\mathrm{H} 23, \mathrm{H} 24$ \\
\hline 9 & 144.4 & & & & \\
\hline 10 & 161.0 & & & & \\
\hline 11 & - & & & & \\
\hline 12 & 127.4 & & & & \\
\hline 13 & 167.4 & & & & \\
\hline 14 & - & & & & \\
\hline 15 & 108.2 & $8.26, \mathrm{~s}$ & & $\mathrm{C} 12, \mathrm{C} 13, \mathrm{C} 20$ & $\mathrm{H} 20$ \\
\hline 16 & 128.8 & & & & \\
\hline 17 & - & & & & \\
\hline 18 & 137.6 & $7.90, \mathrm{~s}$ & & $\mathrm{C} 16, \mathrm{C} 20$ & \\
\hline 19 & - & & & & \\
\hline 20 & 131.4 & $7.37, \mathrm{~s}$ & & $\mathrm{C} 16, \mathrm{C} 18$ & H15 \\
\hline 21 & 43.6 & & & & \\
\hline 22 & 146.7 & $\begin{array}{c}6.22, \mathrm{dd},(10.8 \\
17.2)\end{array}$ & & & \\
\hline $23 \mathrm{a}$ & 113.7 & $5.10, \mathrm{dd},(10.8 ; 16)$ & & $\mathrm{C} 21$ & \\
\hline $23 b$ & 113.7 & $5.03, \mathrm{dd},(17.2 ; 16)$ & & $\mathrm{C} 21$ & \\
\hline 24 & n.d. & $1.32, \mathrm{~s}$ & & C3, C21 & $\mathrm{H} 4, \mathrm{H} 8$ \\
\hline 25 & 30.9 & $1.29, \mathrm{~s}$ & & $\mathrm{C} 3, \mathrm{C} 21$ & \\
\hline
\end{tabular}


biosynthesis of the mycotoxins meleagrin and oxalin, ${ }^{21}$ which are produced by some Penicillium species, as well the N-hydroxylated form of the glandicoline A, which is derived from some rearrangements reactions of the diketopiperazine alkaloid roquefortine $\mathrm{C}$, another mycotoxin with neurotropic and antibiotic activities, commonly found in Penicillium spp. cultivation. ${ }^{22}$

\section{Biological assay}

The mycelial extract in methanol of the Penicillium sp. strain PBR.2.2.2 exhibited antimicrobial activity at $500 \mu \mathrm{g} \mathrm{mL}^{-1}$ against Staphylococcus aureus and compound $\mathbf{1}$ was active at $100 \mu \mathrm{g} \mathrm{mL}^{-1}$ against $S$. aureus, Micrococcus luteus and Escherichia coli. The other six compounds did not showed activity against those bacteria. The glandicoline B exhibited a low bactericide activity if compared with the positive controls norflaxacin and tetracycline. While other compounds of the roquefortine/oxaline biosynthesis ${ }^{22}$ have been showed important biological activities, e. g. the cytotoxicity of some diterpenoid derivates of meleagrin ${ }^{8}$ and the bactericide activity of the roquefortines, ${ }^{23}$ there is no previous report about biological activities for glandicoline B.

\section{EXPERIMENTAL}

\section{Instrumental and chromatographic materials}

The optical rotation was measured in $\mathrm{MeOH}$ using a Perkin Elmer $^{\circledR} 241$ polarimeter with a sodium lamp at $598 \mathrm{~nm}$ at $33{ }^{\circ} \mathrm{C}$. $1 \mathrm{D}$ and 2D NMR experiments were obtained in $\mathrm{CD}_{3} \mathrm{OD}$ and $\mathrm{CDCl}_{3}$ (Cambridge Isotope ${ }^{\circledR}$ ) using a Varian ${ }^{\circledR}$ INOVA 500 spectrometer operating at $500 \mathrm{MHz}$ for ${ }^{1} \mathrm{H}$ and $125 \mathrm{MHz}$ for ${ }^{13} \mathrm{C}$. TMS was used as internal standard. Spectra of APCI-IT-MS were obtained in an LCQ fleet equipment $\left(\right.$ Thermo $^{\circledR}$ ) operating in positive mode. The analysis of product ions until $\mathrm{MS}^{4}$ was performed by collision-induced dissociation (CID) with energy of $15 \mathrm{eV}$. TLC was performed using silica gel 60 PF254 $\left(\right.$ Merck $^{\circledR}$ ) and spots were visualized under UV light and sprayed vanillin- $\mathrm{H}_{2} \mathrm{SO}_{4}$ reagent, followed by heating at $100{ }^{\circ} \mathrm{C}$. The fractionation was performed in CC using normal phase silica $230-400$ mesh $\left(\right.$ Merck $\left.^{\circledR}\right)$. Anlytical HLPC was performed on a Shimadzu SPDM10AVP diode array detector, LC-10AD pumps, SIL-10ADVp auto sampler and UV-vis SPD-6A detector. Preparative HPLC: Shimadzu UV detector LC-6AD pump, UV SPD-10AV detector and manual injector. Analytical HPLC column: Phenomenex, Luna, Phenyl-Hexyl ( $5 \mu \mathrm{m}, 250 \mathrm{~mm}$ x $4.60 \mathrm{~mm}$ ); preparative HPLC column: Phenomenex, Luna, Phenyl-Hexyl (5 m, 250 mm x 21.20 mm).

\section{Isolation and identification of Penicillium sp. PBR.2.2.2}

Roots of M. flexuosa were collected in June 2008 in the campus of the Universidade Federal do Amazonas (UFAM) in the city of Manaus, Brasil, and authenticated by the Herbarium of the UFAM where a voucher specimen (no. 7282) is deposited. The plant material was washed with detergent and sterile water for external cleaning, then fragments were immersed in $70 \%$ alcohol, later in $3 \%$ hypochlorite solution and finally in sterile water. ${ }^{12}$ After this process, plant fragments were inoculated in Petri dishes containing ISP2-agar medium and incubated up to thirty days. At 24-h intervals, after the third day, fragments of agar containing hyphae of the newly born endophytic fungi were removed and transferred to test tubes with the same medium and incubated at $26{ }^{\circ} \mathrm{C}$ for 30 days. After this period the mitosporic fungi were purified by the Tween technique. ${ }^{12}$ The identification of the isolated endophytic fungus Penicillium sp. PBR.2.2.2 was conducted by microculture of it in different solid media: PDA (potato, dextrose and agar), ISP2 (international Streptomyces project number 2) and Czapek-agar. The vegetative and reproductive micromorphological structures observed in the slides of the culture with 24 and $48 \mathrm{~h}$ in optical microscope were compared with the literature. ${ }^{24}$ A voucher was deposited in the fungal collection of the GEMMA group of the UFAM.

\section{Cultivation and extraction}

Penicillium sp. strain PBR.2.2.2 was grown on PDA culture medium at $26{ }^{\circ} \mathrm{C}$ for 8 days. After this period a suspension of its cells was prepared, quantified using McFarland scale and inoculated (50 $\mu \mathrm{L}$ ) in 60 flasks of $1 \mathrm{~L}$ containing $300 \mathrm{~mL}$ of ISP2 liquid medium (10 $\mathrm{g}$ corn starch, $4 \mathrm{~g}$ yeast extract, $10 \mathrm{~g}$ malt, $4 \mathrm{~g}$ dextrose for every $1 \mathrm{~L}$ of distilled water). The cultivation was made at $26{ }^{\circ} \mathrm{C}$ in static mode for 21 days. The mycelial mass $(1.7 \mathrm{~kg})$ was ground and extracted with methanol $(3 \times 1 \mathrm{~L})$ providing $10.5 \mathrm{~g}$ of crude extract.

\section{Isolation of the chemical constituents}

The methanolic extract was submitted to liquid vacuum chromatography on silica gel CC (70-230 mesh). A gradient system elution was applied (hexane:EtOAc 9:1 and 3:7, EtOAc 100\% and $\mathrm{MeOH}$ $100 \%$ ) resulting in 4 fractions which were monitored by silica gel TLC. The both hexane:EtOAc fractions were rechromatographed on a low-pressure silica gel CC (230-400 mesh) (h x $\varnothing=40 \times 2 \mathrm{~cm}$ ) eluted with dichloromethane, ethyl acetate and methanol gradients affording ergosterol 2 (DCM 100\%, 13.4 mg), brassicasterol 3 (DCM:EtOAc 95:5, $16.2 \mathrm{mg}$ ), ergosterol peroxide 4 (DCM:EtOAc 85:15, $34.7 \mathrm{mg}$ ), cerevisterol 5 (DCM:EtOAc 1:1, $4.8 \mathrm{mg}$ ). The EtOAc 100\% fraction was analysed in analytical HPLC. Isocratic elution with $50 \% \mathrm{MeOH}$ at a flow rate of $0.7 \mathrm{~mL} \mathrm{~min}^{-1}$ gave the best chromatographyc resolution. According to the scaling up from analytical HPLC conditions, the EtOAc $100 \%$ fraction was submitted to reverse phase preparative HPLC, with $50 \% \mathrm{MeOH}$ at $21.3 \mathrm{~mL} \mathrm{~min}^{-1}$ and UV detection at $245 \mathrm{~nm}$, to afford $\mathbf{1}(23.5 \mathrm{mg})$. The $\mathrm{MeOH} 100 \%$ fraction when rechromatographed in a low-pressure silica gel CC (230-400 mesh) (h $\times \varnothing=30 \times 1.5 \mathrm{~cm}$ ) eluted with dichloromethane, ethyl acetate and methanol gradient afforded mannitol $6(12.9 \mathrm{mg})$ and $1-O-\alpha-D-$ glucopyranoside 7 (4.2 $\mathrm{mg})$.

Glandicoline $B(\mathbf{1})$ : yellow gum; $[\alpha]_{\mathrm{D}}+23.8($ c 0.14 in $\mathrm{MeOH})$; ${ }^{1} \mathrm{H}-\mathrm{NMR}\left(500 \mathrm{MHz}, \mathrm{CD}_{3} \mathrm{OD}\right),{ }^{13} \mathrm{C}(125 \mathrm{MHz}), \mathrm{COSY}$ and $\mathrm{HMBC}$ : Table 1; APCI-MS daughter ions (15 eV): $\mathrm{m} / z, 420(5)\left([\mathrm{M}+\mathrm{H}]^{+}, 403\right.$ (5), 374 (2), 351 (10), 334 (20), 316 (10), 289 (100).

\section{Antimicrobial assay}

The minimal inhibitory concentrations (MICs) were determined by microbroth dilution assays as recommended by the Subcommittee on Antifungal Suscetibility Testing of the US National Committee for Clinical Laboratory Standards (NCCLS). The assays were performed on 96 well plates with $100 \mu \mathrm{L}$ of Mueller Hinton Broth (MHB), 100 $\mu \mathrm{L}$ of test compound or fraction solutions and $5 \mu \mathrm{L}$ of test bacterial suspensions at $1.0 \times 10^{7} \mathrm{UFC} \mathrm{mL}^{-1}$. The fungus compounds or fractions assayed were dissolved in dimethylsulfoxide (DMSO) at initial concentration of $500 \mu \mathrm{g} \mathrm{mL} \mathrm{L}^{-1}$ and the incubation was made at $37^{\circ} \mathrm{C}$ for $24 \mathrm{~h}$. The microorganisms tested were E. coli, S. aureus, Pseudomonas aeruginosa, M. luteus and Bacillus cereus. The bioactivities were recorded as blue coloration in the wells after use of resazurin dye. The bacteriostatic or bactericidal effects of the metabolites assayed were observed by inoculation of the well materials on Mueller Hinton Agar plates after the tests. Positive controls norflaxacin $\left(4 \mu \mathrm{g} \mathrm{mL} \mathrm{m}^{-1}\right)$ and tetracycline $\left(4 \mu \mathrm{g} \mathrm{mL}^{-1}\right)$ with the negative control DMSO were used during the tests. 


\section{CONCLUSIONS}

Penicillium sp. strain PBR.2.2.2 is the first reported endophytic fungus from the palm tree $M$. flexuosa. From its bioactive mycelium extract were isolated seven compounds, including the rare indole alkaloid glandicoline B, which exhibited moderate antimicrobial activities against S. aureus, M. luteus and E. coli. This alkaloid, an intermediate in the biosynthesis of the roquefortine/oxaline pathway, ${ }^{22}$ was isolated previously only once, from Penicillium glandicola, a species found in Russian permafrost soil, ${ }^{20}$ a totally different environment from that from where obtained the Penicillium sp. strain PBR.2.2.2. All NMR and MS data of glandicoline B, new in the literature, confirm the structure previously described.$^{20}$ The bioactive properties of the fungus PBR.2.2.2 can be attributed, at least in part, to glandicoline $\mathrm{B}$, the major component of its mycelium and a potential agent for bactericide application.

\section{SUPLEMENTARY MATERIAL}

The NMR ${ }^{1} \mathrm{H}, \mathrm{HMBC}, \mathrm{HSQC}, \mathrm{COSY}, \mathrm{NOE}, \mathrm{NMR}{ }^{13} \mathrm{C}$ and MS spectra of $\mathbf{1}$ are available with free access in a pdf file, at http:// quimicanova.sbq.org.br.

\section{ACKNOWLEDGEMENTS}

The authors are grateful to Fundação de Amparo à Pesquisa do Estado do Amazonas (FAPEAM) and Conselho Nacional de Desenvolvimento Científico e Tecnológico (CNPq) for the financial support.

\section{REFERENCES}

1. Gunatilaka, A. A.; J. Nat. Prod. 2006, 69, 526.

2. Strobel, G. A.; Microbes Infect. 2003, 5, 544.

3. Rull, V.; Rev. Paeobot. Palynol. 1998, 100, 122.

4. Williams, C. A.; Harborne, J. B.; Phytochemistry 1973, 12, 2430.

5. Passos, M. A. B.; Mendonça, M. S.; Acta Amazonica 2006, 36, 436.
6. Sonjak, S.; Frisvad, J. C.; Gunde-Cimerman, N.; Microbiol. Ecol. 2006, 52, 207.

7. Stierle, D. B.; Stierle, A. A.; Patacini, B.; J. Nat. Prod. 2007, 70, 1820.

8. Du, L.; Li, D.; Zhu, T.; Cai, S.; Wang, F.; Xiao, X.; Gu, Q.; Tetrahedron 2009, 65, 1033.

9. Gao, S. S.; Li, X. M.; Li, C. S.; Proksch, P.; Wang, B. G.; Biorg. Med. Chem. Lett. 2008, 21, 2897.

10. Kwon, O. E.; Rho, M. C.; Song, H. Y.; Lee, S. W.; Chung, M. Y.; Lee, J. H.; Kim, Y. H.; Lee, H. S.; Kim, Y. K.; J. Antibiot. 2002, 55, 1008.

11. Singh, S. B.; Zink, D. L.; Guan, Z.; Collado, J.; Pelaez, F.; Felock, P. J.; Hazuda, D. J.; Helv. Chim. Acta 2003, 86, 3380.

12. Souza, A. Q. L.; Souza, A. D. L.; Astolffi-Filho, S.; Belém-Pinheiro, M. L.; Sarquis, M. L.; Moura, M. I.; Pereira, J. O.; Acta Amazonica 2004, 34, 195.

13. Shirane, N.; Takenaka, H.; Ueda, K.; Hashimoto, Y.; Katoh, K.; Ishii, H.; Phytochemistry 1996, 41, 1308.

14. Bruun, T.; Phytochemistry 1976, 15, 1180.

15. Yue, J. M.; Chen, J.; Lin, Z.; Sun, H. D.; Phytochemistry 2001, 56, 806.

16. Kawagishi, H.; Katsumi, R.; Sazawa, T.; Mizuno, T.; Hagiwara, T.; Nakamura, T.; Phytochemistry 1988, 27, 2779.

17. Branco, A.; Santos, J. D.; Pimentel, M. A. M.; Osuna, J. A. T.; Lima, L. S.; David, J. M.; Ind. Crop. Prod. 2010, 32, 510.

18. Agrawal, P. K.; Phytochemistry 1992, 31, 3307.

19. Kawai, K.; Nozawa, K.; Nakajima, S.; Iitaka, Y.; Chem. Pharm. Bull. 1984, 32, 94.

20. Kozloviskii, A. G.; Vinokurova, N. G.; Reshetilova, A. T.; Sakhavoskii, V. G.; Baskunov, B. P.; Seleznev, S. G.; Appl. Biochem. Microbiol. 1994, 30,414 .

21. Reshetilova, T. A.; Vinokurova, N. G.; Khmelenina, V. N.; Kozlovsky, A. G.; Microbiology 1995, 64, 29.

22. Overy, D. P.; Nielsen, K. F.; Smedsgaard, J.; J. Chem. Ecol. 2005, 31, 2373.

23. Aninat, C.; Hayashi, H.; André, F.; Delaforge, M.; Chem. Res. Toxicol. 2001, 14, 1259

24. Kiffer, E.; Morelet, M.; The Deuteromycetes - Mitosporic FungiClassification and Generic Keys, $2^{\text {nd }}$ ed., Science Publishers: New York, 1999. 